\title{
NILAI-NILAI PENDIDIKAN AKHLAK PERSPEKTIF IMAM NAWAWI AL-BANTANI DALAM KITAB NASHAIH $A L$-'IBAD
}

\section{THE VALUES OF MORAL EDUCATION ON THE PERSPECTIVE OF IMAM NAWAWI AL-BANTANI IN THE BOOK OF NASHAIH AL-'IBAD}

\author{
Abdul Khamid \\ Institut Agama Islam Negeri Salatiga, Indonesia \\ Email: abdulkhamied33@gmail.com
}

\begin{abstract}
Abstrak
Sebagaimana diketahui bahwa Imam Nawawi merupakan seorang ulama salaf pemikir yang menghasilkan karya-karya besar yang terkenal, beliau merasa bahwa sangat pentingnya seorang pribadi yang memiliki keimanan yang kuat, kesempurnaan aqidah dan akhlak serta pendidikan yang berkualitas dan memadai harus dimiliki oleh setiap orang dalam aktivitas kehidupan sehari-hari. Maka penelitian ini bertujuan untuk mengetahui dan mengkaji apa saja yang menjadi nilai pendidikan dalam kitab Nashaih al-'Ibad, pertanyaan yang akan dijawab melalui penelitian ini adalah (1) bagaimana diskripsi pemikiran Imam Nawawi tentang nilia-nilai pendidikan akhlak; (2) bagaimana relevansi pada akhlak pemikiran imam Nawawi terhadap anak pelajar sekarang. Untuk menjawab pertanyaan tersebut maka penelitian ini menggunakan pendekatan kepustakaan. Metode penelitian yang digunakan yaitu dengan jenis kepustakaan, sedangkan sumber data primer dari kitab Nashaih al'Ibad, dan sumber skundernya dari buku-buku lain yang berhubungan dengan penelitian ini. Adapun teknis analisis data menggunakan metode induktif dan deduktif. Temuan penelitian ini menunjukkan bahwa nilai pendidikan akhlak dalam kitab Nashaih al-'Ibad karya Imam Nawawi al-Bantani ini sangat dibutuhkan bagi dunia pendidikan sekarang ini. Dari sini diharapkan akan terwujud sebuah pribadi yang memiliki akhlak mulia, berbudi pekerti yang luhur dan berkeimanan yang kuat.
\end{abstract}

Kata Kunci: Imam Nawawi al-Bantani, nilai-nilai pendidikan moral, Nashaih al-'Ibad

\begin{abstract}
As we know that Imam Nawawi is a scholars of salaf thinkers who produce famous great works, he feels that it is very important that a person who has strong faith, perfection of aqidah and akhlak also quality and adequate of education must be possessed by everyone in their life. So the aims of this study is to find out and examine what education in the Nashaih al-Ibad, the questions that will be answered through this research are: (1) how is the description of Imam Nawawi's thoughts about the values of moral education; (2) how is the relevance of the value of moral education by Imam Nawawi's thinking towards students today. To answer this question, this research using a library approach. The
\end{abstract}


research method used is the type of literature, while the primary data source from the Nashaih al-'Ibad book, and the source of the secondary from other books related to this research. The technical data analysis using inductive method and deductive method. The findings of this research indicate that the value of moral education in the Nashaih al'Ibad by Imam Nawawi al-Bantani is very much needed for the world of education today. From this it is hoped that a person who has good character and strong friendship will be realized.

Keywords: Imam Nawawi al-Bantani, moral education values, Nashaih al-'Ibad

\section{A. Pendahuluan}

Islam adalah Agama yang dibawa Rasulullah Muhammad SAW sebagai pedoman hidup umat manusia dan pendidikan bagi manusia dan seluruh alam ini. Rasulullah SAW sebagai utusan yang menyempurnakan akhlak manusia, karena beliau dalam hidupnya penuh akhlak-akhlak yang mulia dan sifat-sifat yang baik. ${ }^{1}$

Agama Islam sangat memperhatikan masalah akhlak, melebihi perhatiannya dari hal-hal yang lain. Perhatian itu sampai sedemikian rupa, sehingga akhlak sebagai salah satu pokok tujuan risalah. Akhlak merupakan lambang kualitas manusia, masyarakat, dan umat. Karena itulah akhlak yang menentukan eksistensi seorang muslim, Akhlak merupakan sifat yang dekat dengan iman. Baik buruknya akhlak menjadi salah satu syarat sempurna atau tidaknya keimanan manusia. Orang yang beriman kepada Allah akan membenarkan dengan seyakin-yakinnya akan ke-Esaan Allah, meyakini bahwa Allah mempunyai sifat dengan segala kesempurnaannya dan tidak memiliki sifat kekurangan, ataupun menyerupai sifat-sifat makhluk ciptaan-Nya. ${ }^{2}$

Oleh karena itu, pendidikan akhlak merupakan bagian besar dari isi pendidikan Islam, posisi ini terlihat dari kedudukan al-Qur'an sebagai referensi paling penting tentang akhlak bagi kaum muslimin baik individu, keluarga, masyarakat, dan umat. Akhlak merupakan buah Islam yang bermanfaat bagi manusia dan kemanusiaan serta membuat hidup dan kehidupan menjadi baik. Akhlak merupakan alat kontrol psikis dan

\footnotetext{
${ }^{1}$ Umar Abdul Djabbar, Ringkasan Nurul Yaqin Terjemahan, Jilid 1 (Surabaya: Toko Kitab Ahmad Nabhan, t.t.), 3 .

${ }^{2}$ Zaenuri dan Adib Al Arif Siroj, Hebatnya Akhlak di Atas Ilmu dan Tahta (Surabaya: Bintang Books, 2009), 2.
} 
sosial bagi individu dan masyarakat. Tanpa akhlak, manusia tidak akan berbeda dari kumpulan binatang. ${ }^{3}$

Karena harkat manusia ditentukan oleh akhlaknya. Akhlaknya yang sudah membentuk menjadi kepribadian akan memberikan jati diri yang agung. Jati diri tidak terbentuk dengan sendirinya, tetapi perlu adanya langkah-langkah untuk mengukirnya. Mengukir jati diri di waktu kecil seperti mengukir batu, butuh ketekunan sampai akhir hayat. ${ }^{4}$ Akan tetapi berbanding terbalik dengan apa yang terjadi remaja sekarang pergaulan sudah sangat mengkhawatirkan, karena sudah sangat banyak hal-hal yang buruk yang dilakukan oleh remaja. Lingkungan memberikan kontribusi yang sangat besar dalam kehidupan, dan dapat membentuk suatu kebiasaan terhadap seseorang. ${ }^{5}$

Oleh karena itu, orang tua harus lebih memperhatikan anak-anaknya dalam soal pendidikan, terutama pendidikan tentang akhlak. Supaya mereka tidak mudah terpengaruh dengan keadaan lingkungan yang buruk seperti saat ini. Pada masa yang akan datang kelak, mereka akan menjadi pilar-pilar penerus perjuangan yang memiliki tingkah laku (akhlak) yang baik, menjadi penerus bangsa negara, dan juga agama.

Salah seorang ulama yang mengkaji dan memberikan pendidikan akhlak secara mendalam adalah Imam Nawawi al-Bantani. Beliau adalah seorang ulama besar dalam bidang keilmuan salah satunya adalah pendidikan akhlak. Sejarah menyebutkan bahwa ia dikenal kuat dalam mengamalkan ilmu dan hidup zuhud, dan sangat sabar menjalani kehidupan yang serba kekurangan. Beliau juga jarang tidur malam, rajin beribadah dan menulis berbagai kitab salah satu karyanya yang sering dikaji adalah Nashaih al-'Ibad. Kitab ini tergolong praktis, di dalamnya terdapat berbagai ulasan-ulasan yang berhubungan dengan nilai-nilai pendidikan akhlak beserta dalil-dalilnya (dasardasarnya), yang kemudian bisa dijadikan acuan untuk mempengaruhi dan memformulasikan nilai-nilai pendidikan akhlak dalam kehidupan sehari-hari para siswa (pelajar).

Dari uraian di atas, penulis sangatlah tertarik ingin lebih jauh mengkaji tentang nilai-nilai pendidikan akhlak pada pemikiran Imam Nawawi al-Bantani melalui sebagian karyanya yang cukup fundamental yaitu kitab Nashaih al-'Ibad yang di

\footnotetext{
${ }^{3}$ Munzier dan Ali, Watak Pendidikan Islam (Jakarta Utara: Farika Agung Insani, 2008), 89.

${ }^{4}$ Achmad Mubarok dan Syamsul Yakin, Buku Seri Akhlak Mulia Mengukir Jati Diri (Bandung: PT. Imperial Bhakti Utama, 2011), 3.

${ }^{5}$ Abu Bakar Jabir al-Jazairi, Minhaj al-Muslim, Terj. Mustofa, Aini, Amir Hamzah Fachrudin dan Kholif Mutaqin (Malang: PT. Megatama Sofwa Pressindo, t.t.), 223.
} 
Abdul Khamid: Nilai-nilai Pendidikan Akhlak Perspektif Imam Nawawi al-Bantani dalam Kitab Nashaih al-'Tbad

dalamnya terdapat beberapa uraian tentang pendidikan akhlak. Penulis berusaha untuk menyusun sebuah artikel tentang nilai-nilai pendidikan akhlak persepektif Imam Nawawi al-Bantani dalam kitab Nashaih al-'Ibad.

\section{B. Pendidikan Akhlak}

Pendidikan dapat ditinjau dari dua segi pandangan masyarakat dan dari pandangan induvidu. Dari segi pandangan masyarakat, pendidikan berarti pewarisan kebudayaan dari generasi tua kepada generasi muda agar hidup masyarakat itu tetap berkelanjutan nilai-nilai budaya yang ingin disalurkan dari generasi ke generasi. Dilihat dari kacamata induvidu, pendidikan berarti pengembangan potensi-potensi yang terpendam dan tersembunyi. Manusia mempunyai berbagai kesanggupan yang mana ketika pandai menggunakannya bisa berubah menjadi emas dan intan dengan kata lain kemakmuran manusia tergantung pada keberhasilan pendidikannya dalam mencari dan menggarap kekayaan yang terpendam pada setiap individu. ${ }^{6}$

Pengertian pendidikan merupakan bagian yang tidak dapat dipisahkan dan kehidupan manusia. Jalaluddin mengatakan bahwa pendidikan sebagai salah satu kebutuhan, fungsi sosial, sebagai bimbingan, sarana pertumbuhan yang mempersiapkan dan membukakan serta membentuk disiplin hidup. ${ }^{7}$ Ada juga yang mengartikan pendidikan sebagai transmisi dan seseorang kepada orang lain baik keterampilan, seni maupun ilmu. Pendidikan merupakan upaya manusia dewasa membimbing yang belum dewasa untuk mencapai kedewasaan. Pendidikan adalah bimbingan atau pimpinan secara sadar oleh si pendidik terhadap perkembangan jasmani dan rohani siswa menuju terbentuknya keperibadian yang utama. ${ }^{8}$

Jadi, pendidikan itu merupakan sesuatu yang mendasar bagi manusia yang harus diberikan, karena pendidikan kunci kesuksesan dalam menjalankan kehidupan ini, baik berkeluarga, bermasyarakat, maupun berbangsa dan bernegara.

Adapun akhlak secara bahasa berasal dari bahasa Arab akhlaqun merupakan bentuk jamak dari kata khuluqun yang artinya: budi pekerti, tingkah laku atau tabiat.

\footnotetext{
${ }^{6}$ Mansur Isna, Diskursus Pendidikan Islam (Yogyakarta: Global Pustaka Utama, 2001), 38.

${ }^{7}$ Jalaluddin, Teologi Pendidikan (Jakarta: PT Raja Grafindo Persada, 2003), 67.

${ }^{8}$ Mansur Isna, Diskursus..., 38.
} 
Gambaran batin manusia, meliputi jiwa dan sifat-sifatnya. Sedangkan gambaran bentuk luarnya raut muka, warna kulit, tinggi, rendah tubuh. ${ }^{9}$

Pengertian akhlak secara istilah dapat disimak dari beberapa pendapat atau pengertian sebagai berikut:

Muhammad Jamaluddin al-Qasimi mendefinisikan akhlak sebagai keadaan yang tertanam di dalam jiwa, yang mewujudkan atau melahirkan perbuatan-perbuatan dengan mudah dan gampang tanpa butuh berfikir atau diangan-angan terlebih dahulu. ${ }^{10}$

Menurut Imam al-Ghozali, akhlak adalah sifat yang tertanam dalam jiwa yang menimbulkan macam-macam perbuatan dengan gampang dan mudah tanpa memerlukan pemikiran dan pertimbangan. ${ }^{11}$

Muhaimin Mujib menyatakan akhlak adalah nilai-nilai dan sifat-sifat yang tertanam dalam jiwa, dengan sorot dan timbangannya seorang dapat menilai perbuatan baik atau buruk, untuk kemudian memilih melakukan atau meninggalkan. ${ }^{12}$

Jadi, pendidikan akhlak adalah suatu usaha mengembangkan diri sesuai kebutuhan yang diyakini benar oleh seseorang atau kelompok sehingga menjadi kebiasaan yang terbentuk dengan sendirinya tanpa dipikirkan dan tanpa direncanakan terlebih dahulu. Dengan demikian akan tercapailah tatanan kehidupan dunia yang damai dan sejahtera antara penghuninya saling mengasihi, menghormati, juga melindungi serta mengajak ke arah perilaku yang diridhai Allah dan utusannya.

\section{Deskripsi Pemikiran Imam Nawawi tentang Nilai Pendidikan Akhlak dalam kitab Nashaih al-'Ibad}

Salah satu kitab yang terkenal karya Imam Nawawi al-Bantani yang berbicara tentang pendidikan akhlak secara mendalam adalah kitab Nashaih al-'Ibad yang berisikan nasehat-nasehat orang alim, yang luas ilmu pengetahuannya, seorang hafiz, Karakteristik pemikiran pendidikan akhlak Imam Nawawi al-Bantani dalam kitab tersebut dapat digolongkan dalam corak praktis yang tetap berpegang teguh pada alQur`an dan Hadits.

\footnotetext{
${ }^{9}$ Muhaimin, et.al., Dimensi-dimensi Studi Islam (Surabaya: Karya Abditama, 1994), 56.

${ }^{10}$ Muhammad Jamaludin al-Qasimi, Mauizhah al-Mu'minin (Jakarta: Dar al-Kutub Al-Islamiyah, 2005), 4

${ }^{11}$ Muhammad al-Ghazali, Al- 'Ilm, Terj. Muhammad Baqir (Bandung: Karunia, 1996), 52.

${ }^{12}$ Muhaimin, et.al., Dimensi-dimensi..., 56.
} 
Pendidikan budi pekerti sering diartikan dengan pendidikan akhlak. Budi pekerti dan akhlak merupakan dua istilah yang memiliki kesamaan esensi, walaupun akhlak memiliki cakupan pengertian watak, sikap, sifat, moral yang tercermin dalam tingkah laku baik dan buruk yang terukur oleh norma-norma sopan santun, tata karma dan adat istiadat. Sedangkan akhlak diukur dengan menggunakan norma-norma agama. ${ }^{13}$

Pemikiran-pemikiran Imam Nawawi al-Bantani tentang akhlak di dalam kitab Nashaih al-'Ibad memang sangat luas. Di dalam kitab ini terdapat banyak nilai-nilai pendidikan akhlak yang bisa ditanamkan dan diterapkan kepada para pelajar, agar mereka mengetahui dan bisa melaksanakannya dalam kehidupan sehari-hari. Di antara nilai-nilai pendidikan akhlak yang dapat penulis analisis dari kitab Nashaih al-'Ibad karya Imam Nawawi al-Bantani menjadi tiga pembagian besar yaitu: (1) akhlak terhadap Allah SWT; (2) akhlak terhadap diri sendiri; dan (3) akhlak terhadap masyarakat.

1. Pendidikan Akhlak terhadap Allah SWT

a. Pendidikan rela dengan keputusan Allah SWT

Manusia harus selalu dibiasakan untuk rela terhadap apa saja yang sudah menjadi keputusan Allah, karena rela dengan keputusan Allah SWT adalah merupakan buah dari rasa cinta kepadaNya. Dengan itu pula seseorang akan selalu memiliki sikap selalu memiliki perasangka baik kepada Allah SWT. Dalam kitab Nashaih al-'Ibad dikatakan:

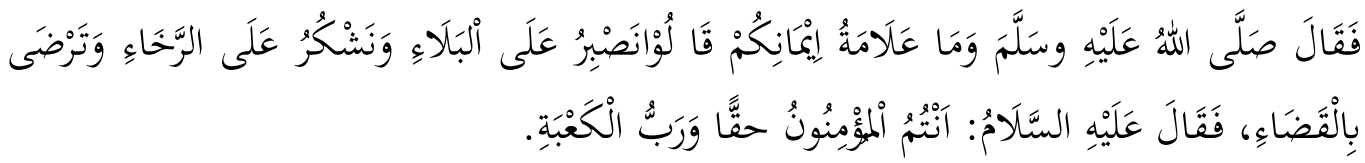

Nabi bertanya: "apakah tanda keimanan kalian? Para sahabat menjawab: kami bersabar dalam menghadapi musibah, kami bersyukur atas nikmat di waktu kelapangan, dan rela menerima semua ketetapan Allah, lalu Nabi bersabda: kalau begitu kalian benar-benar orang mukmin yang sebenarnya. Demi Tuhan Pemilik Kabah."

Rela dengan keputusan Allah adalah meyakini bahwa seluruh perbuatan Allah terjadi pada pihak yang paling tepat, paling adil, paling baik dan paling sempurna

b. Pendidikan untuk selalu cinta terhadap Allah SWT

\footnotetext{
${ }^{13}$ Ahmad, Implementasi Akhlak Qur'ani (Bandung: PT. Telekomunikasi Indonesia, 2002), 34.

${ }^{14}$ Muhammad Nawawi ibn 'Umar al-Jawi, Nashaih al-'Ibad (Semarang: Karya Putra, t.t.), 13.
} 
Allah SWT adalah Yang Maha Agung untuk dicintai, Yang Maha Mulia untuk dicintai, Yang Maha Perkasa untuk dicintai, Yang Maha Sempurna untuk dicintai serta Yang Maha Tinggi untuk dicintai. Dialah Yang Maha Pengampun yang mengampuni sebanyak apa pun dosa dan yang menutupi sebesar apa pun aib, Dia Yang Maha Mulia yang nikmat-nikmat-Nya tidak mampu untuk disyukuri seluruhnya, dosa-dosa manusia kepada-Nya, senantiasa naik sementara karunia-Nya senantiasa turun, kebaikan-Nya meliputi seluruh makhluk-Nya, dan kesempurnaan serta keindahan-Nya membuat hanya Dialah yang layak untuk dicintai dan disembah. Demi Allah, tidaklah seorang mukmin dapat merasakan manis yang seperti manisnya cinta dan iman kepada-Nya, tidak pula dia mendapatkan kemuliaan yang lebih tinggi dan lebih mulia dari pada penghambaan diri kepada-Nya yang disandangnya. Dalam kitab Nashaih al-'Ibad dikatakan:

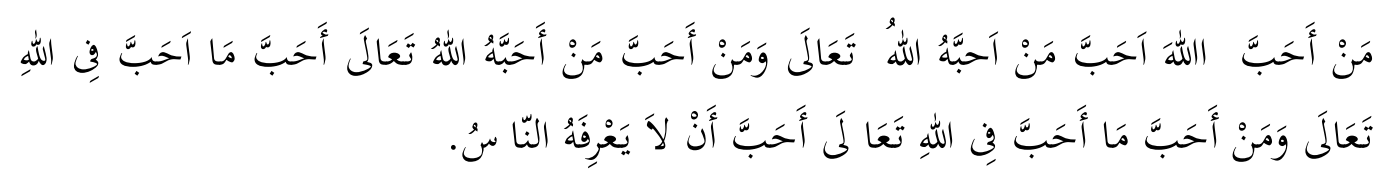

"Barang siapa mencintai Allah, maka ia akan mencintai orang yang Allah cintai, dan barang siapa mencintai orang yang Allah cintai, maka ia akan mencintai sesuatu karna Allah, dan barang siapa mencintai sesuatu karena Allah, maka ia akan berusaha agar amalnya tidak diketahui orang lain." 15

Adapun tanda-tanda cinta kepada Allah:

1) Kecondongan hati yang terus menerus kepada yang dicintai, maka jangan sampai hati terlalaikan dari Allah SWT. dalam cinta kepada-Nya.

2) Lebih mengutamakan ketaatan kepada-Nya dan beribadah serta menghadapkan diri sepenuhnya kepada-Nya, dan mendekatkan diri kepada-Nya, dari pada segala kesenangan dunia dan apa-apa yang menyertainya.

3) Menyukai dan memperbanyak zikir kepada-Nya, serta mengingatkan manusia agar berzikir kepada Allah SWT.

4) Hendaknya menyerahkan sepenuh diri kepada-Nya, hingga tidak tersisa sedikit pun. Maka seluruh tekad, semangat, perbuatan, pikiran, harta, dan waktu seluruhnya untuk Allah SWT. serta untuk menggapai keridhaan-Nya.

Seorang yang menuntut ilmu hendaklah cinta kepada Allah karena Allah adalah sang maha segala-galanya, maha memahamkan dan memudahkan dalam segala hal,

\footnotetext{
${ }^{15}$ Ibid., 18.
} 
sehingga ketika sang maha pencipta mencintai orang yang mencintai-Nya, maka apapun yang diinginkan pasti akan diberikan termasuk jalan dimudahkanya dalam menuntut ilmu.

2. Pendidikan berakhlak terhadap diri sendiri

a. Pendidikan untuk selalu bersikap wara'

Wara' adalah meninggalkan yang meragukan, menentang yang membuat tercela, mengambil yang lebih terpercaya, mengarahkan diri kepada yang lebih hati-hati. Singkatnya, wara' adalah menjauhi yang syubhat dan mengawasi yang berbahaya.

Wara' merupakan senjata sakti perjuangan agama. Dengan wara' yang menjadikan ciri para ulama yang mengamalkannya ilmunya. Pahamilah bahwasannya orang yang memperoleh sesuatu yang haram, maka sedikitlah pertolongan dari Allah untuk beramal shalih. Di dalam kitab Nashaih al- 'Ibad dikatakan:

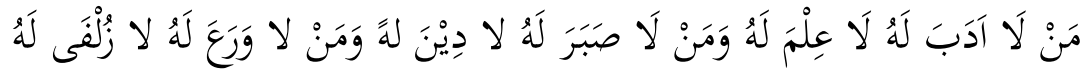

"Orang yang tidak memiliki sopan santun berarti dia tidak berilmu, orang yang tidak sabar, berarti ia tidak menghayati agamanya. Dan orang yang tidak memiliki sifat wara', berarti tidak memiliki derajat."16

Wara' yaitu menjauhkan diri dari dosa, maksiat, dan syubhat (perkara yang tidak diketahui halal dan haramnya, seorang hamba tidak akan mencapai tingkat muttaqin, hingga dia meninggalkan apa yang bahaya baginya, karena takut terhadap hal yang bahaya baginya. ${ }^{17}$

b. Pendidikan untuk selalu bersabar

Seorang yang berakal ialah yang sabar menempuh segala macam kesulitan, berhati tabah menghadapi segala macam rintangan serta berani mengorbankan jiwa untuk menyingkirkan apa saja yang menghalangi usahanya dengan sungguh keberanian. ${ }^{18}$ Karena sabar merupakan sendi dasar yang harus dimiliki selama masih hidup di dunia, maka termasuk juga akhlak yang mulia. Dalam kitab Nashaih al-'Tbad dikatakan:

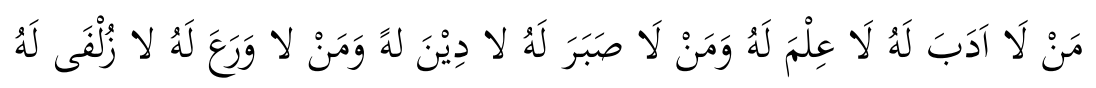

\footnotetext{
${ }^{16}$ Ibid., 11.

${ }^{17}$ Sayyid Abdullah bin Alwi bin Muhammad al-Hadad, Risalah al-Mua'awanah, Terj. oleh Ihsan dan Suchaimi, Ainul Ghoerry, Jalan Menempuh Ridho Allah (Surabaya: Al-Hidayah, 2010), 93.

${ }^{18}$ Musthafa al-Ghalayini, Bimbingan Menuju Akhlak Luhur, Terj. Abdai Rathomy (Semarang: PT. Karya Toha Putra, 2000), 5.
} 
"Orang yang tidak memiliki sopan santun berarti dia tidak berilmu, orang yang tidak sabar, berarti ia tidak menghayati agamanya. Dan orang yang tidak memiliki sifat wara', berarti tidak memiliki derajat."19

Allah SWT berfirman-Nya:

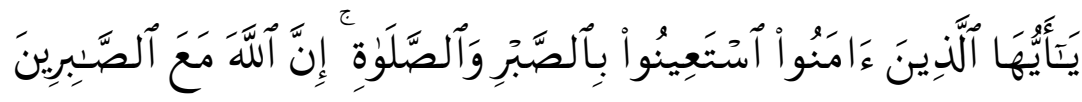

"Wahai orang-orang yang beriman! mohonlah pertolongan kepada Allah dengan sabar dan shalat. Sungguh Allah bersama orang-orang yang sabar." (Q.S. AlBaqarah: 153)

Ulama' membagi sabar menjadi tiga:

1) Sabar dalam musibah, yaitu kerelaan menerima kehendak Allah yang pada awalnya terasa tidak nyaman seperti sakit, kurang harta, ketakutan, kelaparan, bencana alam dan sebagainya.

2) Sabar dalam ibadah, kerelaan melakukan kehendak Allah yang wujud dalam perintah-perintah-Nya.

3) Sabar dalam maksiat, kerelaan diri menerima ujian melakukan hal-hal yang menjadi larangan-Nya. ${ }^{20}$

Oleh karena itu, sabar adalah separuh iman, sebab tidak satupun maqam iman kecuali disertai kesabaran. Bahkan Allah akan memberikan derajat yang tinggi dan kebaikan, dan menjadikannya sebagai buah dari kesabaran.

3. Pendidikan berakhlak terhadap masyarakat

a. Pendidikan untuk selalu jujur

Pengertian jujur ialah benar, benar dalam arti setiap perkataan dan perbuatan yang dilakukan tidak saling bertentangan. Seseorang muslim yang jujur, maka perbuatanya tidak pernah menyimpang dari perkataannya. Islam mengajarkan kepada kita untuk selalu berbuat jujur. Jujur adalah suatu sifat atau sikap seseorang yang menyatakan sesuatu dengan sebenar-benarnya, tanpa ditambah atau dikurangi. ${ }^{21}$

Sikap jujur termasuk akhlak yang terpuji dan mulia. Anak yang jujur berarti orang yang memiliki akhlak yang mulia dan merupakan sifat dan sikap yang terpuji dan

\footnotetext{
${ }^{19}$ Muhammad Nawawi ibn 'Umar al-Jawi, Nashaih al-'Ibad...

${ }^{20}$ Ahmad Sultoni, Sang Maha Segalanya Mencintai Sang Mahasiswa (Salatiga: STAIN Salatiga Press, 2007), 153.

${ }^{21}$ Sumitro, Akidah Akhlak (Jakarta: PT. Listafariska Putra, 2005), 26.
} 
disenangi oleh Allah SWT. ${ }^{22}$ Kejujuran yang dibangun antar sesama merupakan tali pengikat hubungan soial, ekonomi, dan politik yang kemudian dapat mendorong pertumbuhan dan perkembangan suatu bangsa. Di dalam kitab Nashaih al-'Ibad dikatakan:

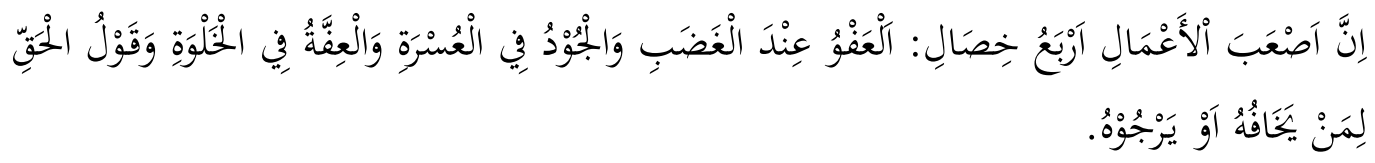

"Amal perbuatan yang paling berat ada empat: memberi maaf ketika marah, suka berderma di saat melarat, 'iffah (memelihara diri dari yang haram) ketika sendirian, dan berkata benar (jujur) terhadap orang yang ditakuti atau orang yang diharapkan jasanya. ${ }^{23,}$

Allah SWT. berfirman:

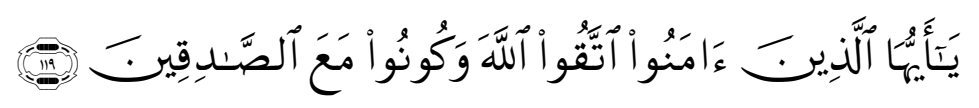

"Wahai orang-orang yang beriman! Bertaqwalah kepada Allah, dan bersamalah kamu dengan orang-orang yang benar." (Q.S. Al-Taubah: 119)

Ucapan dapat menjadi agung dan tinggi nilainya, apabila sesuai dengan kenyataan yang ada, akan tetapi dapat menjadi kecil atau rendah nilainya, apabila tidak sesuai dengan kenyataan yang ada. Benar tidaknya dan baik buruknya suatu perkataan itulah yang menyebabkan seseorang dipuji dan dihormati orang lain, atau bahkan akan dicela dan dihinakan. ${ }^{24}$

Maka hendaklah seorang selalu berkata dan berbuat dengan jujur dalam pergaulan dalam bermasyarakat sesuai dengan petunjuk di atas agar terhindar dari celaan masyarakat, meninggikan kehormatan, dan yang paling penting menjalankan ajaran suri tauladan yang baik bagi manusia yakni Rasulullah SAW. dan mengamalkan sifat tersebut.

b. Pendidikan untuk selalu adil

Hendaknya manusia selalu berbuat adil dalam perkataan maupun perbuatan. Memilih keadilan di dalam seluruh urusannya sampai keadilan menjadi akhlaknya, menjadi sifat yang tidak dapat terpisah darinya. Maka keluarlah darinya kalimat-kalimat 15.

${ }^{22}$ Sugiyono, Sejarah Kebudayaan Islam (Semarang: PT. Tiga Serangkai Pustaka Mandiri, 2012),

${ }^{23}$ Muhammad Nawawi ibn 'Umar al-Jawi, Nashaih al- 'Ibad..., 29

${ }^{24}$ Musthafa al-Ghalayini, Bimbingan ..., 160. 
dan perilaku yang adil, jauh dari kesewenang-wenangan, kezhaliman, maupun penyelewengan.

Keadilan hendaknya ditegakkan di mana saja dan kepada siapa saja. Setiap muslim diperintahkan untuk berbuat adil kepada diri sendiri, kepada keluarga, kepada teman-teman, dan kepada siapapun. Orang yang diperlakukan adil akan merasa senang, puas, dan merasa dihargai. Sehingga dengan adanya keadilan akan menciptakan masyarakat yang aman dan tentram. Di dalam kitab Nashaih al- 'Ibad dikatakan:

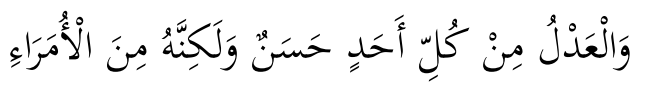

"Sikap adil dari setiap orang itu bagus, tapi dari pejabat lebih bagus. ${ }^{25}$

Keadilan memiliki beberapa aspek yang dapat ditunjukkan, antara lain:

1) Adil menghukumi antar manusia, dengan memberikan hak-hak kepada masing-masing yang berhak dan barang-barang yang menjadi haknya.

2) Adil di antara para istri dan anak-anak dengan tidak memberikan kelebihan dan mengutamakan salah satu atas lainnya atau kepada sebagian atas sebagian yang lainnya.

3) Adil di dalam perkataan, hingga tidak bersumpah palsu, berkata dusta atau batil.

4) Adil di dalam berkeyakinan, sehingga tidak meyakini hal-hal yang tidak benar, tidak jujur dan hati tidak ragu-ragu pada sesuatu yang tidak benar dan tidak nyata. $^{26}$

Seorang pelajar hendaklah memilih keadilan di dalam seluruh urusannya sampai keadilan menjadi akhlaknya, menjadi sifat yang tidak dapat terpisah darinya. Oleh sebab itu, hendaknya selalu berusaha untuk dapat berbuat adil, dan jangan sekali-kali berbuat zalim. Berbekal dengan sifat adil sejak dini yang mana suatu saat menjadi pemimpin bisa berlaku kepada rakyat dengan adil, orang-orang yang berada dalam kekuasaan adalah tanggung jawab seorang pemimpin.

\footnotetext{
${ }^{25}$ Muhammad Nawawi ibn 'Umar al-Jawi, Nashaih al- 'Ibad, 20.

${ }^{26}$ Abu Bakar Jabir al-Jazairi, Minhaj al-Muslim..., 242.
} 


\section{Relevansi Nilai Pendidikan Akhlak Kitab Nashaih al-'Ibad dalam Konteks Kehidupan Pelajar Sekarang}

Dari keterangan di atas, banyak nilai-nilai akhlak yang dapat diambil dari kitab Nashaih al-'Ibad dan dapat diterapkan kepada para pelajar sekarang, untuk menata kehidupan mereka yang saat ini sedang dalam kemerosotan moral.

Pendidikan bagi kehidupan umat manusia merupakan kebutuhan mutlak yang harus dipenuhi sepanjang hayat. Tanpa pendidikan sama sekali mustahil suatu kelompok manusia dapat hidup berkembang sejalan dengan cita-cita untuk maju, sejahtera dan bahagia menurut konsep pandangan hidup mereka.

Individu manusia lahir tanpa memiliki pengetahuan apapun, tetapi ia telah dilengkapi dengan fitrah yang memungkinkannya untuk menguasai berbagai pengetahuan dan peradaban. Dengan memfungsikan fitrah itulah ia belajar dari lingkungan dan masyarakat orang dewasa yang mendirikan institusi pendidikan. ${ }^{27}$

Tujuan pendidikan adalah membentuk manusia berkualitas secara lahiriyah dan bathiniyah. Secara lahiriyah pendidikan menjadikan manusia bermanfaat bagi dirinya dan orang lain, serta dapat menentukan arah hidupnya ke depan. Sedangkan cara bathiniyah pendidikan diharapkan dapat membentuk jiwa-jiwa berbudi, tahu tata krama, sopan santun dan etika dalam setiap gerak hidupnya baik personal maupun kolektif. Hal ini mangandung arti bahwa pendidikan akan membawa perubahan pada setiap orang sesuai dengan tata aturan.

Akhlak Islam adalah suatu keyakinan terhadap nilai-nilai ketuhanan di dalam kehidupan nyata semata-mata untuk meraih ridha Allah SWT. Akhlak merupakan aktifitas lahir sekalian batin. Aktifitas lahir Nampak dalam budi pekerti terpuji dan aktifitas batin nampak dalam bentuk keteguhan dan kekuatan jiwa, menumbuhkan optimisme dan tekat yang kuat. ${ }^{28}$

Pendidikan akhlak yang ada pada kitab Nashaih al-'Ibad sangatlah relevan jika diterapkan untuk pelajar sekarang, karena dalam pembahasannya tentang pendidikan akhlak. Sehingga apabila diterapkan pada para pelajar, mereka akan menjadi orang yang cerdas hati dan pikirannya serta menjadi lebih kuat dalam mengarungi dan menghadapi tantangan kehidupan yang akan datang.

\footnotetext{
${ }^{27}$ Munzier dan Ali, Watak Pendidikan Islam..., 1.

${ }^{28}$ Muhaimin, et.al., Dimensi-dimensi..., 57.
} 
Adapun nilai-nilai pendidikan akhlak yang relevan dapat diambil dan diterapkan terhadap dunia pendidikan sekarang dari kitab Nashaih al-'Ibad karya Imam Nawawi al-Bantani antara lain dapat diuraikan sebagai berikut:

Pertama, rela dengan keputusan Allah adalah meyakini bahwa seluruh perbuatan Allah terjadi pada pihak yang paling tepat, paling adil, paling baik dan paling sempurna. Selalu rela dengan apa yang sudah menjadi keputusan Allah SWT ini, relevan sekali dengan pendidikan para pelajar sekarang. pendidikan ini harus diberikan kepada para pelajar saat ini. Karena kebanyakan mereka saat ini belum seperti itu. Mereka masih memiliki prasangka buruk terhadap tuhannya ataupun orang lain apabila ada suatu kejelekan menimpanya. Dengan pendidikan ini mereka akan tertuntut menjadi manusia yang bijaksana dalam segala hal yang menimpa padanya, karena mereka sadar semuanya itu adalah memang sudah keputusan dari Allah SWT, dan itulah yang memang terbaik untuknya.

Kedua, pendidikan untuk selalu cinta kepada Allah SWT sangat relevan dengan konteks pelajar sekarang. Para pelajar diberikan sebuah pengertian akan pentingnya cinta kepada Allah SWT dengan tujuan bisa direalisasikan dalam kehidupan, saat ini seringkali melanggar aturan-aturan yang ada, baik itu aturan yang dibuat manusia maupun aturan yang dibuat oleh Sang Pembuat manusia (Allah SWT), itu semua dikarenakan kurangnya rasa cinta kepada Allah SWT. Sebab rasa cinta yang dalam kepada Allah, itu akan membuat manusia mau melakukan hal-hal yang baik. Walaupun hal itu berat dan susah, mereka akan tetap rela melakukannya, karena bukti rasa cinta adalah mau melakukan hal-hal yang disukai oleh yang dicintai (Allah). Dan Allah sangat mencintai orang orang yang berbuat kebaikan.

Ketiga, pendidikan sikap wara' ini sangat relevan jika ditanamkan kepada para pelajar sekarang, karena kenyataan bahwa yang menghantarkan mereka pada hal-hal yang tidak sesuai dengan norma-norma agama maupun kehidupan adalah tidak adanya pengetahuan tentang sikap ini. Sehingga mereka terbiasa melakukan hal-hal yang mereka anggap itu adalah sesuatu yang biasa dan remeh, akan tetapi berpotensi pada dosa besar, seperti mulanya para pelajar sekarang saling memandang, berpegangan tangan, berboncengan tanpa ada alasan, berpelukan, berciuman dan lain sebagainya, yang semuanya itu belum ada ikatan yang sah. Yang kesemuanya itu adalah perbuatanperbuatan yang bisa menjatuhkan pada perzinaan. Maka dari itu, sangatlah cocok untuk 
diajarkan kepada pelajar sekarang akan pentingnya bersikap wara' dalam kehidupan setiap hari, baik di sekolah maupun lingkungan luar sekolah supaya terhindar dari dosadosa besar yang dianggap hal yang remeh.

Keempat, pendidikan untuk selalu jujur sangat relevan dengan kehidupan dalam sebuah kemasyarakatan, orang bisa dikatakan baik oleh masyarakat dikarenakan dari sifat kejujuran dalam bersosialisali kepada masyarakat, karena banyaknya dijumpai seorang pemuda dalam bergaul tidak jujur dan mengedepankan kepentingannya sendiri, guna menyukseskan kepentingannya sendiri, sesuatu yang burukpun dilakukannya dengan berkata yang tidak jujur, padahal jujur adalah kunci sebuah kesuksesan. Oleh karenanya, hal demikian perlunya penanaman sikap jujur dalam pendidikan untuk selalu berkata jujur atas segala sesuatu perkataan, sangat dibutuhkan untuk merubah sikap mereka yang sering tidak jujur dalam bermasyarakat, karena sekali tidak jujur maka akan mengulang kedua, ketiga dan selanjutnya.

\section{E. Kesimpulan}

Dalam kitab Nashaih al- 'Ibad beliau memaparkan betapa pentingnya pendidikan pada segala sendi kehidupan. Manusia harus memiliki pendidikan sebagai pembeda dari makhluk lain. Bahkan pentingnya pendidikan dalam Islam sampai diibaratkan seperti dua sisi dari sekeping mata uang, artinya Islam dan pendidikan mempunyai hubungan filosofis yang sangat mendasar dan tidak dapat dipisahkan.

Dari pemaparan Imam Nawawi Al-Bantani, nilai-nilai pendidikan akhlak yang ada pada kitab Nashaih al-'Ibad dapat dikelompokkan menjadi tiga, yaitu pendidikan berakhlak kepada Allah SWT, pendidikan berakhlak kepada diri sendiri, dan pendidikan berakhlak terhadap masyarakat.

\section{F. Daftar Pustaka}

Ahmad. Implementasi Akhlak Qur'ani. Bandung: PT. Telekomunikasi Indonesia, 2002. Al-Ghalayini, Musthafa. Bimbingan Menuju Akhlak Luhur. Terj. Abdai Rathomy. Semarang: PT. Karya Toha Putra, 2000.

Al-Ghazali, Muhammad. Al-'Ilm. Terj. Muhammad Baqir. Bandung: Karunia, 1996.

Al-Hadad, Sayyid Abdullah bin Alwi bin Muhammad. Risalah al-Mua'awanah. Terj. oleh Ihsan dan Suchaimi, Ainul Ghoerry. Jalan Menempuh Ridho Allah. Surabaya: Al-Hidayah, 2010. 
Al-Jawi, Muhammad Nawawi ibn 'Umar. Nashaih al-'Ibad. Semarang: Karya Putra, t.t.

Al-Jazairi, Abu Bakar Jabir. Minhaj al-Muslim. Terj. Mustofa, Aini, Amir Hamzah Fachrudin dan Kholif Mutaqin. Malang: PT. Megatama Sofwa Pressindo, 1998.

Al-Qasimi, Muhammad Jamaludin. Mauidzah al-Mu'minin. Jakarta: Dar al-Kutub AlIslamiyah, 2005.

Djabbar, Umar Abdul. Ringkasan Nurul Yaqin Terjemahan. Jilid 1. Surabaya: Toko Kitab Ahmad Nabhan, t.t.

Isna, Mansur. Diskursus Pendidikan Islam. Yogyakarta: Global Pustaka Utama, 2001.

Jalaluddin. Teologi Pendidikan. Jakarta: PT Raja Grafindo Persada, 2003.

Mubarok, Acmad dan Yakin, Syamsul. Buku Seri Akhlak Mulia Mengukir Jati Diri. Bandung: PT. Imperial Bhakti Utama, 2011.

Muhaimin, et.al. Dimensi-dimensi Studi Islam. Surabaya: Karya Abditama, 1994.

Munzier dan Ali. Watak Pendidikan Islam. Jakarta Utara: Farika Agung Insani, 2008.

Sugiyono. Sejarah Kebudayaan Islam. Semarang: PT. Tiga Serangkai Pustaka Mandiri, 2012.

Sultoni, Ahmad. Sang Maha Segalanya Mencintai Sang Mahasiswa. Salatiga: STAIN Salatiga Press, 2007.

Sumitro. Akidah Akhlak. Jakarta: PT. Listafariska Putra, 2005.

Zaenuri dan Siroj, Adib Al Arif. Hebatnya Akhlak di Atas Ilmu dan Tahta. Surabaya: Bintang Books, 2009. 